\title{
Critical Factors for Transferring and Sharing Tacit Knowledge within Lean and Agile Construction Processes
}

\begin{abstract}
Purpose - The purpose of the paper is to investigate the critical success factors (CSFs) associated with the effectiveness of transfer and sharing of tacit knowledge in lean and agile construction processes.

Design/Methodology/Approach - The study identifies ten critical success factors that initiate the transferring and sharing of tacit knowledge. The CSFs are validated through quantitative study. This study recruited project managers, executives, consultants, and other managers that are directly involved in the management of a construction project. It recruits the respondents those have background and experience from disciplines such as lean construction, agile construction, Construction Supply Chain (CSC) and KM in lean, agile and CSC. The data collected through selfadministrative questionnaire, is categorised as ordinal data, analyzed in SPSS with Frequency and Kruskal-Wallis H test and Spearman's correlation analysis. A rank order analysis is performed to establish the level of importance of those factors.
\end{abstract}

Findings -Initially, 'Trust between construction organisations' is identified as the foremost CSF. Moreover, other CSFs such as, motivation, leadership capabilities, business strategies and organisational capabilities follow trust.

Originality/Value - This is the first study that investigates and establishes the CSFs that are essential to initiate transferring and sharing tacit knowledge in a lean and in an agile construction processes.

Keywords - Construction Supply Chain (CSC), Transferring and Sharing Tacit Knowledge, Knowledge Management, Lean and Agile Construction Process, Lean Construction, Organisational Learning

\section{Introduction}

Throughout the $21^{\text {st }}$ century, our view regarding knowledge management (KM) Thomas, (2013) has drastically changed (Reich et. al., 2012). Over the past decade, construction projects have become more demanding in terms of process improvement (Egbu, et. al., 2005). Therefore, lean and agile processes is greatly considered to improve the efficiency of construction processes (Lin and Tserng, 2003). However, tacit knowledge transfer is neglected (Anumba, et. al., 2008). Consequently, there are several problems and challenges indicated by researchers such as a lack of trust and commitment, a lack of Public-Private Partnerships (PPP), a lack of efficient processes and a lack of standardisation. However, Alashwal et.al., (2011) suggest that problems such as a disunited supply chain, a lack of integration and collaboration and insufficient KM systems are either dependent or related to each other. CSCs are fragmented due to the lack of process integration and collaboration (Alashwal et.al., 2011; Ribeiro and Fernandes, 2010; Hughes et. al., 2002 and Orange et.al., 1994). Nevertheless, Taylor, (2012) suggested that an insufficient KM system discourages process integration, and 
collaboration in a CSC. Furthermore, (Zhang, 2012) suggests that the existing KM systems have failed to transfer and share tacit knowledge. That leads to lessened collaboration, a breakdown in trust between partners and inefficient process integration in CSCs (Hughes et.al., 2002).

Even so, today, the UK construction sector, about three million employees jointly makes an immense brain-bank (Saini, 2015). BIS, (2011) revealed that skill loss in the UK construction industry has not recovered since 1990's downturn. The current recession reinforces the skill loss and leads to questioning of the capabilities of the UK construction sector (Baldauf and Hubbard, 2011). Now, the ongoing economic downturn continues to lead to the stagnation of the construction sector's growth in terms of skills, employment, innovation and business capabilities (Lomax et.al., 2013). Moreover, construction SMEs has seen the continuous downfall in, skill enhancement Therefore; deficiency in skills establishes itself as a negative efficiency in collaboration within a CSC. Kivrak and Arslan, (2008) highlighted that KM brings efficient collaboration in CSCs. However, only a handful of studies focused on KM in a CSC. Those studies focus only on KM either in lean or in an agile CSC. None of the studies focused on KM in both the lean and agile processes. Ribeiro and Fernandes, (2010) expressed that joint application of lean and agile principles brings iterative development with a strong emphasis on supply chains (SC) partners in terms of skill advancement.

Still, the notion of transferring and sharing tacit knowledge in construction processes proceeded informally over the past decade. There is little empirical research within this area, especially in the context of KM in lean and agile processes. Transferring and sharing tacit knowledge is considered a critical task for managers involved in construction projects (Arif et.al., 2015). That is because of the lack of understanding of how-to approach (to drive knowledge sharing) and the factors that drive the success of transferring and sharing tacit knowledge. A reason of that is the nature of construction industry that is generally categorised by high fragmentation and low productivity (Xue et.al., 2007), which remains characterised by adversarial practices and disjointed SC relationships (Briscoe and Dainty, 2005). The fragmentation process in traditional contracting practice further hinders the integration of construction knowledge among contractors (Nawi et. al., 2014).

To eliminate negative impact of fragmentation, the framework agreement (2011) sets the growth objectives of construction sector but emphasised that these could only be achieved while sharing knowledge and acquiring skills. Vinodh et.al., (2009) said, the construction industry requires an integrated approach to implementing lean and/or agile in a construction process. However, implementing lean and agile requires knowledge sharing approach. But, lack of awareness and understanding of KM frameworks, specifically the transferring and sharing tacit knowledge remains a problem. Therefore, the lean and agile implementation within the construction processes is underperforming. One of the reason of underperformance is that tier 1 is forcing the lean implementation to tier 2 and tier 3 of a CSC (Aziz et al., 2016). The other reason is the unrealistic effort of implementing lean and agile on construction projects as a whole instead of process levels. Therefore, there is lack of KC is performed at process levels. Resultant, 99 percent of construction knowledge stays within the mind of people (Egbu et. al., 2005). Underpinning theories of lean (Sacks et al., 2009; Womack and Jones, 2003; Womack et al., 1990) and agile implementation (Abbas et al., 2008; Christopher and Towill, 2001; Owen and Koskela, 2006) suggests that both concepts works better if implemented for tiny advancements at process levels of a project. Therefore, it is important to study the transfer and sharing of tacit knowledge at construction process levels instead of project levels. To fill the gap in the literature, this study sets out to define the critical factors that drive the transfer and sharing tacit knowledge in lean and agile construction processes. 


\section{Lean and Agile in Construction}

Lean and Agile are often described as two distinct manufacturing paradigms (Krishnamurthy and Yauch, 2007). In this context, Lean as a principle is to add-value to a construction process while relentlessly eliminating waste from each of the task within the current, following and related activities. On the contrary, Agile as a principle is to increase responsiveness of each of the current, following and related activities within a task and, furthermore, within the processes that integrate with other processes. The basic understanding of agility defines how concepts and frameworks are developed. In contrast, agility is used to 'react' (respond to change) (Bredillet, 2013) and at the same time to 'act'. The meaning of agility is context dependent and relates to the role through a process. The term 'react' is mainly to respond to the change and 'act' is often viewed as a decision-making framework.

Agility is often confused or mixed up with flexibility, and dynamic abilities. The definition of flexibility is "the ability to adapt to change". The understanding is similar as to agility. However, there is a fundamental difference. Flexibility refers to one-off changes, and agility is a concept for continual change (Marc Werfs, 2013). That is why there are many definitions of agility exist. Some researchers maintain to define agile as a philosophy. Alistair Cockburn's definition is "Agile implies being effective and manoeuvrable. An Agile process is both light and sufficient. The lightness is a means of staying manoeuvrable. The sufficiency is a matter of staying in the game” (Abbas, et. al., 2008). Boehm (1988) gives more practice-oriented definition, "In general. Agile methods are very lightweight processes that employ short loop cycles; actively involve users to establish, prioritise, and verify requirements; and rely on tacit knowledge within a team contrary to documentation" (Abbas et. al., 2008).

On the other side, lean manufacturing system is often presumed as mass production that cannot easily adapt to changing market conditions (Court, et. al., 2009). The agile paradigm is leans toward customisation and responsiveness to customer demand. Combining and integrating lean and agile principles has proven successful in increasing customer satisfaction and decreasing time and cost to market under uncertain conditions (Rahimnia and Moghadasian, 2010). The key characteristics of lean and agile methods are lean, flexibility and highly iterative development with a strong emphasis on stakeholder involvement (Ribeiro and Fernandes, 2010). However, lean and agile principles may be complementary in the sense that they can join one system to another, for example, integrating lean manufacturing with an agile supply chain. The adoption of "lean" and/or "agile” in construction processes is often known as the "lean and/or agile" construction process (Court et.al., 2009). This combined approach contains the principles of lean and agile processes. Krishnamurthy and Yauch, (2007), concluded that adopting both lean and agile principles in construction production process could be beneficial.

The benefits of integration of lean and agile within construction processes is for level schedule and to open up of opportunities to drive down costs while simultaneously ensuring that downstream should have an agile response that is capable of delivering to an unpredictable change. Separating the choice of either lean or agile process is presented through its attributes (Christopher and Towill, 2001) in table (1) below. The choice of these attributes leads to the choice of lean or agile process. 


\begin{tabular}{|c|c|c|}
\hline Attributes Products/Services & Lean & Agile \\
\hline Typicality & Commodities & Fashion \\
\hline Demand & Predictable & Volatile \\
\hline Variety & Low & High \\
\hline Lifecycle & Long & Short \\
\hline Customer drivers & Cost & Availability \\
\hline Profit Margin & Low & High \\
\hline Contracts & Long-term & Immediate, Short-term \\
\hline Procurement Policy & Material Sourcing & Capacity Sourcing \\
\hline Information enrichment & Highly desirable & Obligatory \\
\hline Forecasting Mechanism & Algorithmic & Consultative \\
\hline Dominant cost & Physical Cost & Marketability cost \\
\hline
\end{tabular}

The attributes (in table 1) of lean and agile processes are adopted by the industries such as, automobile, computing and clothing industries have benefitted from Lean and Agile SCs (Naylor et.al., 1999). However, adopting just lean or agile principles as separate functions in Construction Supply Chains (CSCs), does not solve the existing problems such as a lack of integration, collaboration and partnering in SCs (Saini, 2015). This is because, Lean principles are widely considered to reduce waste and lead-time in a SC (Sacks et. al., 2009). On the other side, agile principles are merely considered as being more responsive to unpredictable demand and markets. Therefore, lean and agile principles require collaboration of the stakeholders in any organisation (Owen and Koskela, 2006). In reality, implementing both the lean and agile processes produces better results (Christopher and Towill, 2001). Since, a construction site is a combination of fabrication and assembly then a construction site should be considered as a manufacturing site that adopts lean and agile principles (Taylor, 2012 and BIS, 2011a). Accounting above arguments, to bring efficiency in a CSC, both lean and agile should be implemented.

\section{Implementation of Lean and Agile in a CSCs}

In a recent study by BIS, (2013), the CSC structure has a minimum of fifty to seventy (Tier 2) suppliers and sub-contractors. A CSC has different level of suppliers that are often categorised as Tier 1 (main contractors with direct commercial relationship with clients) Tier 2 (sub-contractors with direct contract with main contractors) and Tier 3 and beyond (sub-contractors and suppliers working for sub-contractors) (BIS, 2013).

Moreover, a CSC process mapping may be characterised by five main divisions, Mega Process, Major Process, Sub-process, Activity and Task (Capgemini, 2004). A mega process is the highest level of processes identified by an organisation (see figure 1). It is a combination of more than one major process (Capgemini, 2004). A mega process usually forms a core value chain for an organisation. A major process is a sub-division of a mega process and is a combination of several sub-processes. Furthermore, a sub-process is a combination of several activities. An activity is a unit of work performed by one job function at one time with one mode of operation. Each activity can have several tasks. A task is a work step performed to complete an activity.

Lean is geared to improve the construction process and to develop innovative and sustainable construction (Sacks et.al., 2009 and Khalfan et.al., 2007). To get the benefits of lean management, the lean principles require implementation within the entire construction project and within the organisations involved in the project (Saini, 2015). Below Figure 1, is an outcome of the literature on lean and agile construction processes. This presents the implication of lean and agile within one 
mega construction process and its process levels. Organisations handling lean and agile construction projects must implement the lean and agile principles on each aforementioned division (Saini, 2015 and Capgemini, 2004) of a SC. Failure to employ these principles as they apply to all divisions of a SC leads to non-achievement of the stated goals/objectives, as all the SC processes are interconnected (Saini, 2015).

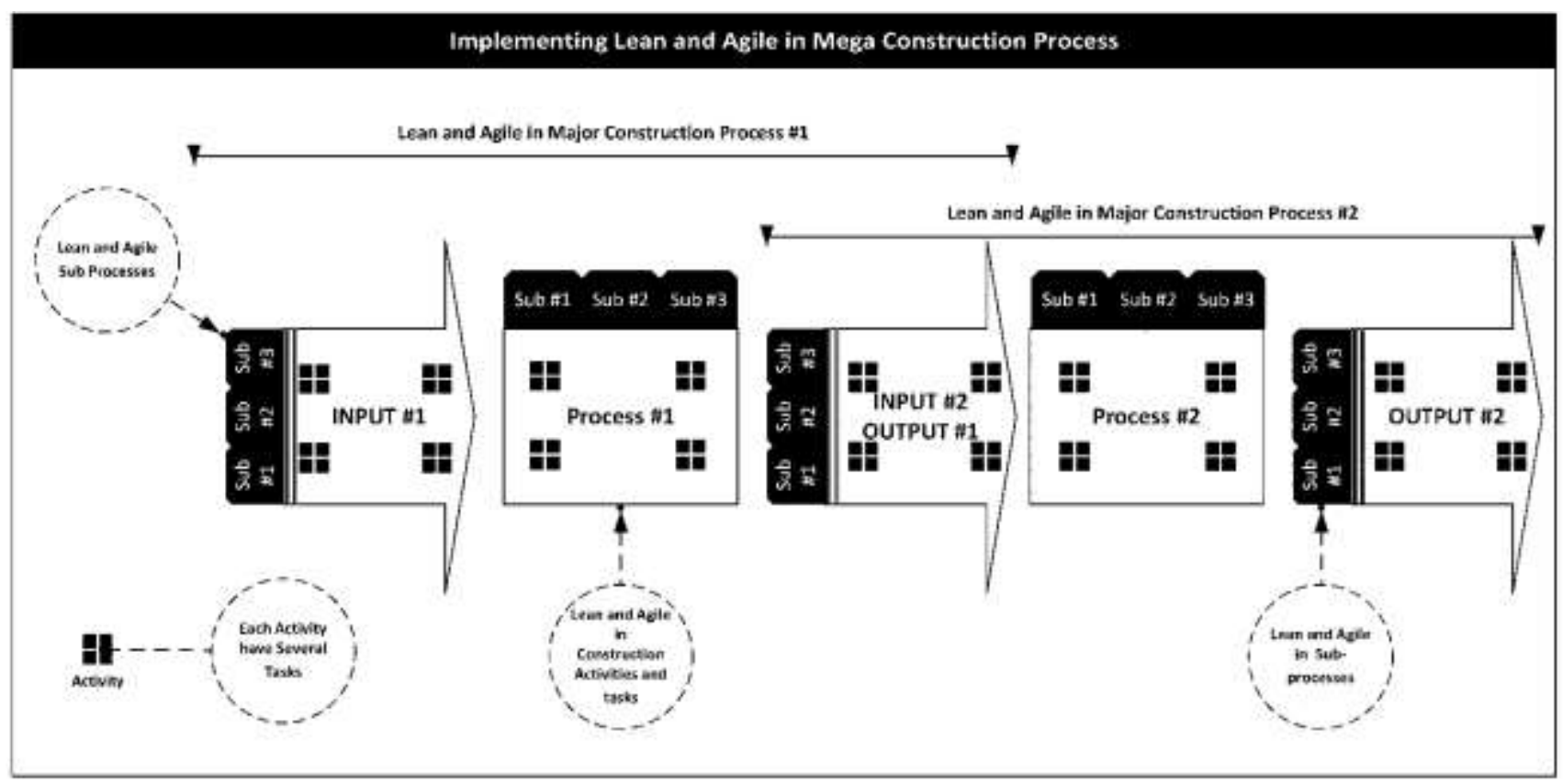

Figure 1: Implementing Lean and Agile in a CSC

\section{Tacit Knowledge Concepts}

As the mental and physical world interacts with each other, tacit knowledge triggers, unfolds and combines as soon as a human being senses, visualise experience, or observes a series of activities (Pathirage, 2007). Tacit knowledge does not remain constant but changes and updates with time and experiences of a source (Polanyi, 2009). "Tacit knowledge is an embedded series of folded thoughts and point of views in a human's mind, which are gained over the time by experience, learning, sensing, analysing, witnessing and observing a process or series of processes within the physical world” (Saini, 2015).

Western philosophers have generally agreed that knowledge is 'justified true belief' (Maier, 2007; Schwartz, 2005; McLean, 2002). Plato said, knowledge could only be obtained by the physical world, which can be sensed by the eyes, the ears and from the whole body (Markie, 2013). However, Aristotle criticised the fact that the knowledge of forms is always occasioned by sensory perception (Maier, 2007). The two forms of knowledge creation, explicit and tacit knowledge, have the key dynamics of knowledge creation. An individual is the principal agent who possesses and processes knowledge. There are three levels of knowledge creation, individual, group and organisational knowledge.

By the mid-1980s, the importance of knowledge as a competitive asset was apparent, even though the classical economic theory ignores knowledge as an asset and most organisations still lack strategies and methods for managing it (Thomas, 2013). Tiwana (1999) said that Drucker warns that no industry or company has a natural advantage or disadvantage; the only advantage it can possess is the ability to exploit universally available knowledge. He describes knowledge as "the window of 
opportunity." The 1980s also saw the development of systems for managing knowledge that relies on work done in artificial intelligence (Reimer and Karagiannis, 2008). However, expert systems, providing such concepts as "knowledge acquisition," (Issa and Haddad, 2008) "knowledge engineering," (Reimer and Karagiannis, 2008) "knowledge-based systems” (Arif et.al., 2015) and computer-based ontologies (Thomas, 2013 ).

However, KM in the built environment mainly deals with the process of creating value from construction operations (Kivrak and Arslan, 2008). Valuable knowledge is available in different forms and media, such as, brilliant ideas of experts, in operation procedures, reporting documents, databases, intranets, etc. KM in the construction processes aims at effectively and systematically collecting and sharing the experience and knowledge through web-based and intranet technologies (Chen and Zhang, 2014). This leads to, reuse of information that minimises the time and cost of problem-solving, and improves process quality during the construction phase of a construction project (Anumba et.al., 2008). By sharing tacit knowledge, the same problems in the construction process do not need to be solved repeatedly (Kivrak and Arslan, 2008). However, a number of studies (presented in below table 2) originated different frameworks of $\mathrm{KM}$ and $\mathrm{KC}$ in construction processes. This study conducts a critical analysis to understand the relevance of those frameworks to transfer and share tacit knowledge in a construction process.

\section{Tacit Knowledge within Construction Processes}

Below table (2) presents the total numbers of studies those are relevant to the theme (transferring and sharing tacit knowledge) of this research. The relevance of this table is to interpret the inclusion and exclusion criteria of the most relevant studies in the field of transferring and sharing tacit knowledge in construction. However, most studies have only focused on effectively managing knowledge transfer and sharing within an organisation. Many of the studies listed below in table (2) fail to quantify the CSFs to transfer and share tacit knowledge. Moreover, none of the study attempts to establish the CSFs specifically in construction projects and within the lean and agile construction processes. However, a few studies closely match with this study is by (Arif et.al., 2015; Martinkenaite, 2011; Narteh 2008; Bou-Llusar and Segarra-Ciprés, 2006; Lin and Tserng, 2003; Goh, 2002). This study reviews those frameworks to understand the CSFs of tacit knowledge transfer and sharing in lean and agile construction processes.

Table 2: List of Existing Studies 


\begin{tabular}{|c|c|c|}
\hline Year & Study Title & Author \\
\hline 2015 & Understanding knowledge sharing in Jordanian construction industry & (Arif et. al., 2015) \\
\hline 2011 & A knowledge chain framework for construction supply chains & (Konukcu, 2011) \\
\hline 2011 & A measurement framework for knowledge transfer in e-learning environment & (Abdullah et. al., 2011) \\
\hline 2011 & Antecedents and consequences of inter-organizational knowledge transfer & (Martinkenaite, 2011) \\
\hline 2009 & $\begin{array}{l}\text { Analysis framework for the interaction between lean construction and building } \\
\text { information modelling }\end{array}$ & (Sacks et. al, 2009) \\
\hline 2008 & Development of a framework for manufacturing excellence & (Sharma and Kodali, 2008) \\
\hline 2008 & $\begin{array}{l}\text { Knowledge transfer in developed-developing country interfirm collaboration- a } \\
\text { conceptual framework }\end{array}$ & (Narteh, 2008) \\
\hline 2008 & $\begin{array}{l}\text { The interaction effects of lean production manufacturing practices, compensation, and } \\
\text { information systems on production costs: a recursive partitioning model }\end{array}$ & (Koh et. al., 2008) \\
\hline 2007 & A knowledge-based analysis and modelling of Dell's supply chain strategies & (Manataki, 2007) \\
\hline 2006 & $\begin{array}{l}\text { Knowledge Integration - a practice of knowledge management in small and medium } \\
\text { enterprises }\end{array}$ & (Jetter et. al., 2006) \\
\hline 2006 & $\begin{array}{l}\text { Knowledge portal for addressing corporate sustainability issue: a conceptual } \\
\text { framework }\end{array}$ & (Renukappa et. al, 2006) \\
\hline 2005 & An agent-based framework for supply chain coordination in construction & (Xue et. al., 2005) \\
\hline 2005 & $\begin{array}{l}\text { Critical success factors for implementing knowledge management in small and } \\
\text { medium enterprises }\end{array}$ & (Wong, 2005) \\
\hline 2005 & $\begin{array}{l}\text { A knowledge management framework for the telecommunication industry: the } \\
\text { KMFTI model }\end{array}$ & (Elashaheb, 2005) \\
\hline 2004 & Information system in supply chain integration and management & $\begin{array}{l}\text { (Gunasekaran and Ngai, } \\
\text { 2004) }\end{array}$ \\
\hline 2003 & Knowledge management and its application to lean construction & (Lin and Tserng, 2003) \\
\hline 2002 & $\begin{array}{l}\text { Managing effective knowledge transfer: an interactive framework and some practice } \\
\text { implication }\end{array}$ & (Goh, 2002) \\
\hline
\end{tabular}

Knowledge sharing in Jordanian construction industry - Arif et.al., (2015) divided fourteen factors into three main factors (Trust, Management and Communication) of knowledge sharing in Jordanian construction industry. This study concludes, "Trust" as the most important factor for knowledge sharing. However, this study is limited to Jordanian construction and inter-organisational knowledge sharing and there is no empirical basis for generalizing. An integrative framework - Goh, (2002) emphasised that one means of driving information transferring and sharing is to encourage a problem seeking and problem-solving culture within an organisation (Wong, 2005; Coakes and Clarke, 2005). The three major factors that influence problem seeking and solving are leadership, high trust, and collaboration between employees. However, that framework is focused on the information sharing within an organisation. Goh's study also establishes the organisational learning and knowledge transfer capabilities are essential for effective knowledge communication. This establishes that choice of knowledge recipient and identification of type of knowledge to transfer are important factors underlying the knowledge transfer (Goh, 2002).

Project oriented KM framework in lean construction - Lin and Tserng, (2003), presented that explicit knowledge comes from the activities and is embedded within the project itself. On the other hand, tacit knowledge is considered as non-activity and non-project knowledge. However, this rejects tacit knowledge should be developed within the activities within a process.

CSFs for implementing knowledge management - Wong, (2005) proposes eleven (11) CSFs for implementing KM in small and medium enterprises. Those include leadership, motivation, business strategies, process, and training of employees. However, this study fails to acknowledge the level of importance of each CSF. The main weakness of this study is the low number of respondents and only provides preliminary indication of appropriateness of these CSFs to implement KM in small and medium enterprises. 
The framework of knowledge transfer - Narteh, (2008), focuses on knowledge transfer within the developed-developing country based inter-firm collaborations. This framework claims to provide a deeper understanding of the characteristics of transferors and transferees. Additionally, this framework presents how knowledge transfer practice influences knowledge transfer across firm borders. In this, the framework identifies two major sources of knowledge. Firstly, organisationally embedded knowledge and, secondly, cognitively or person embedded knowledge is suggested.

Framework of inter-organisational knowledge transfer - Martinkenaite, (2011) emphasises the enablers of inter-organisational Knowledge Transfer such as knowledge attributes, organisational attributes and inter-organisational dynamics. These enablers of knowledge transfer have been seen as the input, which outputs the new knowledge learned and further outcomes, the consequences of the inter-organisational knowledge transfer

Having analysed aforementioned studies (presented in table 2), this study identifies the main critical factors for transferring and sharing knowledge and KM are Leadership, Business Strategies, Trust, Motivation, Training and Development of Employees. The identified CSFs associated with KS in CSCs is given below.

Table 3: CSFs to Transferring and Sharing Tacit Knowledge in Construction Processes

\begin{tabular}{|c|l|l|}
\hline \multicolumn{1}{|c|}{ Critical Success Factor } & \multicolumn{1}{|c|}{ Supported Reading } \\
\hline $\mathbf{1}$ & Trust between the organisations within a CSC & $\begin{array}{l}\text { (Arif et. al, 2015; Lau and Rowlinson, 2011; Lau and Rowlinson, 2010; } \\
\text { Khalfan et. al., 2007; McDermott et. al., 2005 and Weber and Carter, 1998) }\end{array}$ \\
\hline $\mathbf{2}$ & Motivation to share tacit knowledge & $\begin{array}{l}\text { (Arif et. al., 2015; Aiyewalchinmi, 2013; Lau and Rowlinson, 2011; Rose and } \\
\text { Manley, 2011; Lau and Rowlinson, 2010; Tabassi and Bakar, 2009; } \\
\text { McDermott et. al., 2005; Wong, 2005 and Goh, 2002) }\end{array}$ \\
\hline $\mathbf{3}$ & $\begin{array}{l}\text { Leadership capabilities of clients and main } \\
\text { contractors to encourage sharing tacit knowledge }\end{array}$ & $\begin{array}{l}\text { (Balasubramanian, 2012; Succar, 2009; Anumba et. al., 2008; Maier, 2007; } \\
\text { Wong, 2005; Tiwana, 1999b and Egan, 1998; ) }\end{array}$ \\
\hline $\mathbf{4}$ & $\begin{array}{l}\text { Business strategies aligned to share tacit } \\
\text { knowledge in organisations within construction } \\
\text { process }\end{array}$ & $\begin{array}{l}\text { (Arif et. al., 2015; Balasubramanian, 2012; BIS, 2011; Khalfan et. al., 2007; } \\
\text { Wong, 2005; Yusuf et. al, 1999 and Egan, 1998) }\end{array}$ \\
\hline $\mathbf{5}$ & $\begin{array}{l}\text { Organisations within a CSC must have } \\
\text { capabilities to share tacit knowledge }\end{array}$ & $\begin{array}{l}\text { (Manataki, 2007; Schwartz, 2005; Goh, 2002; Tiwana, 1999b; Yusuf et. al., } \\
1999 ; \text { Saad, 1999 and Orange et. al., 1994) }\end{array}$ \\
\hline $\mathbf{6}$ & $\begin{array}{l}\text { Individual involved in construction process must } \\
\text { be capable to share tacit knowledge }\end{array}$ & $\begin{array}{l}\text { (Fischer, 2013; Wu, 2013; Pinto, 2007; Manataki, 2007; Adetunji, 2005; } \\
\text { Wong, 2005; Goh, 2002 and Egan, 1998) }\end{array}$ \\
\hline $\mathbf{7}$ & $\begin{array}{l}\text { Identification of process improvement } \\
\text { opportunity by managers }\end{array}$ & $\begin{array}{l}\text { (Wong 2005; Alavi and Leidner 2001; Kagioglou and Cooper 2012; Goh } \\
\text { 2002; Maier 2007; Arif et al. 2015) }\end{array}$ \\
\hline $\mathbf{8}$ & $\begin{array}{l}\text { Identification of type of knowledge to share } \\
\mathbf{1 0}\end{array}$ & $\begin{array}{l}\text { (Arif et. al., 2015; Rao, 2012; Koçoglu et. al., 2011; Martinkenaite, 2011; } \\
\text { Eppler, 2006; Jetter et. al., 2006; Bolanos et. al., 2005; Mclean, 2002; Alavi } \\
\text { and Leidner, 2001; Goh, 2002 and Orange et. al., 1994) }\end{array}$ \\
\hline $\mathbf{9}$ & $\begin{array}{l}\text { Identification of source of knowledge } \\
\text { Weber et. al., 2005; Quinn, 2005 and Tsai, 2001) }\end{array}$ \\
\hline
\end{tabular}

\section{Discussion of Critical Success Factors}

\section{Trust between Organisation within a CSC}

Trust as a critical success factor leading the success or failure of construction projects is highlighted in both Egan, (1994) and Latham, (1998) reports. There are many definitions of trust based on the assumptions and based on the knowledge of the definer. Trust increases order by reducing complexity, Weber at al., (2005). Trust is built upon the expectations that people have for others or themselves. McDermott et.al., (2005) said, trust is the willingness to rely on the actions of others and being dependent and compromising to their actions. Later, Khalfan et.al., (2007), research entitled, 
'Building trust in construction projects' revealed three main factors of trust as, honest communication (Arif et.al., 2015), reliance and delivery of outcomes. Furthermore, Khalfan et.al., (2007) said, people need to be open, willing to share important information, being honest to reflect the real situation. Trust could only exist if this type of communication existed (Arif et.al., 2015).

The study of (Khalfan et.al., 2007; Lau and Rowlinson, 2011; Ceric, 2012) all mentioned the different levels of trust, e.g. Inter-firm. Intra-firm and Inter-personal levels, (Ceric, 2012) and Strategic, Multiproject, project and task level (Khalfan et.al., 2007). This reveals that, effective communication is required at all levels, to drive trust in CSCs.

Weber et.al., (2005) emphasised that, face-to-face communication plays an important role in initiating trust and that leads to collaboration in inter-personal relationship (Arif et.al., 2015).

\section{Motivation}

Nonaka and Takuchi, (1994) said that breaking down hierarchies in an organisation enables knowledge transfer. Studies such as (Arif et.al., 2015; Wong, 2005; Goh, 2002) consider a motivation and reward system is the major factor for supporting and encouraging knowledge transfer. Goh, (2002) emphasised the qualities and capabilities of the recipients and the characteristics of the knowledge source depends on motivation. Arif et.al., (2015) and Goh, (2002) also emphasised that a recipient's lack of motivation, absorptive capacity and retentive capacity can result in poor transfer of knowledge.

Sharing and transfer of tacit knowledge requires 'trust' between the individuals and organisations within the CSCs (Arif et.al., 2015). The correlation between trust and motivation Weber et.al., (2005) could be significant at the individual level but may not be significant at the organisational level as trusted parties necessarily interpret information in the context of their own motivations. Ceric,(2012) demonstrated that incentives do not drive trust in construction at any level. However, Weber et.al., (2005) said that, to a large degree, trusting-acts will be driven by the trusted party's own dependence, motivation and interests.

\section{Leadership Capabilities}

Leadership support is an essential factor for the approach to building trust in construction (Khalfan et. al., 2007). Moreover, senior management of construction organisations felt that "any policy to pursue the trusting way of working had to come from the director level”. Director level - means the leadership. The role of senior management and leaders is essential to share and transfer knowledge. Since, Egan, (1998) reported that, committed leadership is required to drive forward an agenda for improvement. Later, Anumba et.al., (2008) said, that knowledge sharing include the importance of building trust through leadership. They also said that knowledge leadership is vital for construction industry. They concluded that, KM initiative in construction required effective vision, leadership, coherent strategies and structures and respect for people along with trust (Anumba et.al., 2008).

\section{Business Strategies}

The broad use of term 'business strategies' can be equated with development of a compelling and shared view of KM (Wong, 2005). Business strategies establish pre-implementation success factors of trust initiatives in inter-personal relationship and leadership (Khalfan et.al., 2007; Arif et.al., 2015 and Wong 2005). Business strategies must be aligned at inter-organisational level (Arif et.al., 2015). This also require the capability building of the organisations and individuals to deliver and innovate (Al-Hawamdeh, 2002) trust c) to transfer and share knowledge among them. Wong, (2005) stated, to drive the success of KM, clear and well-planned business strategies are required. However, Thomas, 
(2013) argues that organisations still lack strategies to manage knowledge. Well-planned KM strategies are essential to drive knowledge communication, trust, and motivation and to build individual capability.

\section{Organisational Capabilities}

Organisational maturity includes knowledge sharing in a construction process (Tiwana, 1999). Despite the identified importance only a few studies have been initiated to study the impact, maturity and importance of organisational capability (Keraminiyage, 2009) in construction processes. Organisational capability is a core competency that derives corporate wide learning processes and integrates diverse skills of people and streams of technologies (Yusuf et.al., 1999).

\section{Individual Capabilities}

Tacit knowledge comes from individuals and is hard to articulate (Polanyi, 2009), it is important to motivate and train individuals with the skills that develop communication at the inter-personal, interfirm, and intra-firm levels (Arif et.al., 2015 and Lau and Rowlinson, 2010). Individuals play a key role in knowledge sharing with a construction process. The individual capability is connected to the ability of the person to share personal knowledge. Personal knowledge is the first form of knowledge by having information about someone or something (Kivrak and Arslan, 2008). Sharing personal knowledge leads to development of procedural and propositional knowledge of a process (Polanyi, 2009). However, in construction process, it is important to identify what type of tacit knowledge is to be shared (Saini, 2015 and Rao, 2012).

\section{Identification of process improvement opportunity}

Identifying a process improvement opportunity is a critical factor for a construction process. A process improvement opportunity should be aligned to key performance indicators (KPIs) of a construction projects (Kagioglou and Cooper, 2012). Those KPI's could include efficiency, financial performance and operational performance of a construction process (Maier, 2007). Until the construction managers know which processes need improvement, identifying the type of knowledge is specious (Alavi, 1999). Thus to share knowledge in construction projects a process based view is required (Wong, 2005; )..

\section{Identification of type of knowledge to share}

Arguably, personal knowledge comes only with being familiar with someone or something (Polanyi, 2012). The human senses play a significant role in personal knowledge (Polanyi, 2012 and Pathirage et.al., 2007), for example, someone does not know what "hot" is, until it is sensed. Personal knowledge involves some propositional knowledge (Anumba et.al., 2008)..

Secondly, procedural knowledge is the second kind of knowledge, the knowledge of "how to do" something (Alavi and Leidner, 2001). This type of knowledge clearly differs from propositional knowledge. In an example, it is possible for someone to know what a computer and its components are but does not know how to use them. Using a computer involves processing the skills, which is different from just knowing a collection of facts.

Finally, propositional knowledge is the third form of knowledge and is the primary concern of philosophers. to find and define facts behind an activity or process. Personal and Procedural knowledge both seem to involve some propositional knowledge (Saini, 2015). Still, propositional knowledge is not enough to provide either personal knowledge or procedural knowledge (Aarons, 2005). 


\section{Identification of source of knowledge}

Improving a construction process requires a context-specific knowledge from source. The 'source of knowledge' is cognitive/individually embedded tacit knowledge. (Saini, 2015). The knowledge transfer framework (Narteh, 2008) emphasises, the relationship factors when selecting partners is trust, and interaction. Four transfer processes have been put forward, knowledge conversion (Konukcu, 2011), routing ( Fischer, 2013), dissemination (Coakes and Clarke, 2005) and application to deal with the actual movement of knowledge.

\section{Identification of recipient of knowledge}

A 'knowledge recipient' should have the observation, absorptive, conversational, application, routing, and explanation and dissemination capability to receive the tacit knowledge from the source (Goh, 2002). At the same time, these capabilities are equally important for the source of knowledge (Saini, 2015). However, this study suggests that the main source of knowledge should at least hold observational, communication and explanation capability. This is in order to observe (task and activities), articulate (new knowledge), communicate, and explain new tacit knowledge to the recipient. The reason why a recipient should have explanation capability (Ishibuchi et.al., 2009) is that, on the next stage of knowledge sharing, the recipient will act as the source and will require explanation capability to transfer and/or share the knowledge further upstream in a construction process.

\section{Methodology}

Ten (10) CSF's have been identified in this review. The study adopts a systematic research methodology to investigate those CSF's through quantitative data analysis. As aforementioned, this research aims to investigate the critical success factors associated with the effectiveness of transfer and sharing of tacit knowledge in lean and agile construction processes. The investigation demands the ontological grounds of this research is based on, the personal knowledge that comes from the mental world (Tacit Knowledge) based on the experience of the knowledge holder. Similarly, an investigation of processes (procedural knowledge) could produce various results since the study demands the investigation of individual knowledge to validate the findings from literature review. This establishes that the ontological assumption for this study is subjective, which will authenticate multiple realities. Therefore, this study considers positivist assumptions to test the hypothesis (see below table 4) developed from main findings of CSFs through quantitative data.

To understand the personal and procedural knowledge of respondents, this study collects the data through a survey questionnaire. This study captures personal and procedural knowledge of transferring and sharing tacit knowledge, lean processes and agile process within a CSC. Therefore, below facts are considered for recruiting the respondents.

A typical CSC consists three tiers (1, 2 and 3) (BIS, 2013). In this study, main contractors with a firsthand commercial relationship with the client are termed Tier 1 . Sub-contractors and suppliers with a direct contract with the (Tier 1) main contractor are termed Tier 2. Sub-contractors and suppliers working for sub-contractors are termed Tier 3. The (Tier 3) sub-contractors also employ suppliers and sub-contractors. Therefore, in many cases, there will be a fourth or even fifth tier involved in construction delivery. However, this study does not focus beyond the Tier (2) level because of below facts with the connection to research objectives.

1. This study focuses on the CSFs of KC in a CSC and in lean and agile construction process. Therefore, this study requires that respondents should have knowledge and/or understanding of all 
four disciplines (KM, lean, agile and CSC Process). This restricts the study to employ respondents who are directly involved in the KM, lean, agile and SC Processes, which falls within Tier (1) \& (2) of CSCs.

2. In construction, SC members beyond Tier (2) normally are not involved in implementing lean and/or agile within a construction process (Aziz et. al., 2016). Beyond Tier (2) the manufacturers and suppliers are direct SC of sub-contractors and may not ever be involved as direct stakeholders in a construction project (BIS, 2013).

3. A reports from BIS (2013) reveals, only Project Managers, Main Contractors and the Subcontractors, who are working on the construction site, are the organisations and individuals who have direct involvement in planning and execution of the construction process.

4. Due to the fragmented nature of construction industry and lack of skills and knowledge of aforementioned disciplines in Tier (3) contractors, manufacturers and raw material suppliers also restrict this study to employ respondents' below the SC level named Tier (2).

Resultant this study recruited project managers, executives, consultants, and other managers that are directly involved in the management of a construction project at every stage. However, to fit the purpose of this research the respondents should have background and experience of disciplines such as lean construction, agile construction, CSC and KM in lean, agile and CSC. To understand and establish the sample size for this study, different data sources has been explored.

Due to relatively limited resources available to researchers, large sample sizes become difficult to obtain data from construction industry. On the other side, low sample sizes cast threatening uncertainties and raise questions on the strength of data collected (Root \& Blismas 2003). Hannan \& Anderson (2007) reveals that a minimum number of 30 responses to do statistical analysis. However, some statistical analyses needs about 100 responses. We observed (through statistical analysis) that from 2010 until 2015, a survey response rate from construction industry is $6.5 \%$ to $45 \%$, which calculates an average of $25.75 \%$ response rate. Based this response rate, if a researcher requires minimum 30 responses, then target population is at least 120 respondents, and with maximum requirement of 100.at least 400 respondents is the target population. A target to employ respondents is considered for this study. An anonymous e-survey questionnaire is administrated and the link is published in relevant websites that represents community of practice groups in lean construction, agile construction, CSC and KM and/or KC in construction. In addition, about 250 emails were sent to the top hundred construction companies in the UK. Eighty-three (83) responses received, which are relevant to conduct aforementioned statistical analysis. Since, a link to e-survey were sent through different portals including emails, it is not viable to calculate the response rate.

Responses were received from managers and executives (industry experts with average experience of 15 years and above) and who have collective knowledge and understanding of KM, Construction Processes and CSC Process (analysed through general questions). The overall experience of the respondents gave the research team confidence in the data and indicated that valid inferences can be drawn from this data. A high level of internal consistency for this data is calculated, as Cronbach's alpha $(\alpha)$ is 0.766 . The respondent's experience is the basis for their response.

Questionnaire design and data analysis tools and techniques: to capture the tacit knowledge of aforementioned respondents, a hypothesis is developed for each CSF established earlier through the literature review. The level of criticality is set to 'Critical' for each hypothesis. 
The questionnaire is designed with five (5) point Likert Scale to capture the views of respondents(see below table 4). Below table 4 presents the main hypothesis and the questionnaire design through Likert Scale that produces data in ordinal scale (non-parametric). Having, ordinal scale of data provided the opportunity to analyse in SPSS while running Frequency analysis (to understand the mean, median and mode statistics), Kruskal-Wallis $\mathrm{H}$ Test to test the hypothesis and identify the asymptotic significance of data (against Mann-Witney- because of more than two variables). In addition, Spearman's Correlation analysis to establish the correlation between CSFs (against Pearson's Correlation analysis- because of not normally distributed data).The, hypothesis for each CSF listed in table 4 is set to 'highly critical' to test the hypothesis through, Mean, Median (Frequency, and Kruskal-Wallis H Test) and Asymptotic Significance (Kruskal-Wallis H Test). That provided the opportunity to test the data in four dimensions (including literature review) and finally, an interpretive rank order analysis is performed to establish the essentiality of those factors based on the rank order.

Table 4: Question Design and Data Analysis Techniques

\begin{tabular}{|c|c|c|c|c|c|}
\hline Main Question & \multicolumn{5}{|c|}{$\begin{array}{l}\text { What is the level of criticality of success factors associated with the effectiveness of } \\
\text { Transferring and Sharing Tacit Knowledge(a) in lean process (b) in agile processes? }\end{array}$} \\
\hline Hypothesis & \multicolumn{5}{|c|}{$\begin{array}{l}\text { The level of criticality of success factors associated with the effectiveness of Transferring } \\
\text { and sharing Tacit Knowledge (a) in lean process (b) in agile processes is high. }\end{array}$} \\
\hline Lkert Scale & Not Critical & Of Little Critical & Moderately Critical & Critical & Very Critical \\
\hline Ranking & 1 & 2 & 3 & 4 & 5 \\
\hline Data Type & \multicolumn{5}{|l|}{ Ordinal } \\
\hline Data Analysts Technique/s & \multicolumn{5}{|c|}{ Reliability, Frequencies, Kruskal-Wallis H Test, Spearman's Correlation } \\
\hline & \multicolumn{5}{|l|}{ Hypothesis } \\
\hline 1 & \multicolumn{5}{|c|}{$\begin{array}{l}\text { 'Trust between organisations' in the CSC is highly critical success factor to Transfer and } \\
\text { Share Tacit Knowledge (a) in lean process (b) in agile processes. }\end{array}$} \\
\hline 2 & \multicolumn{5}{|c|}{$\begin{array}{l}\text { 'Motivation' in the CSC is highly critical success factor to Transfer and Share Tacit (a) in lean } \\
\text { process (b) in agile processes. }\end{array}$} \\
\hline 3 & \multicolumn{5}{|c|}{$\begin{array}{l}\text { 'Leadership Capabilities' of clients and main contractors is highly critical success factor to } \\
\text { Transfer and Share Tacit Knowledge (a) in lean process (b) in agile processes. }\end{array}$} \\
\hline 4 & \multicolumn{5}{|c|}{$\begin{array}{l}\text { 'Business strategies' are highly critical success factor aligned to Transfer and Share Tacit } \\
\text { Knowledge (a) in lean process (b) in agile processes. }\end{array}$} \\
\hline 5 & \multicolumn{5}{|c|}{$\begin{array}{l}\text { 'Organisational capabilities' are a highly critical success factor to Transfer and Share Tacit } \\
\text { Knowledge (a) in lean process (b) in agile processes. }\end{array}$} \\
\hline 6 & \multicolumn{5}{|c|}{$\begin{array}{l}\text { Individual capability' is highly critical success factor in (a) in lean process (b) in agile } \\
\text { processes to Transfer and Share Tacit Knowledge. }\end{array}$} \\
\hline 7 & \multicolumn{5}{|c|}{$\begin{array}{l}\text { It is highly critical that construction managers must 'Identify the process improvement } \\
\text { opportunity' to Transfer and Share Tacit Knowledge (a) in lean process (b) in agile processes }\end{array}$} \\
\hline 8 & \multicolumn{5}{|c|}{$\begin{array}{l}\text { Identification of type of Tacit Knowledge' to Transfer and Share Tacit Knowledge (a) in lean } \\
\text { process (b) in agile processes is a highly critical success factor. }\end{array}$} \\
\hline 9 & \multicolumn{5}{|c|}{$\begin{array}{l}\text { Identification of Source of Knowledge' to Transfer and Share Tacit Knowledge (a) in lean } \\
\text { process (b) in agile processes is highly critical success factor. }\end{array}$} \\
\hline 10 & \multicolumn{5}{|c|}{$\begin{array}{l}\text { Identification of Knowledge Recipient' to Transfer and Share Tacit Knowledge (a) in lean } \\
\text { process (b) in agile processes is highly critical success factor. }\end{array}$} \\
\hline
\end{tabular}

Data Analysis

Hypothesis Testing 
Below Table 5 is the data analysis resulting from this study. The frequency analysis and KruskalWallis $\mathrm{H}$ test are based on non-parametric data analysis techniques. This table represents the CSFs as variables (V1 to V10) for presentation purpose.

The data analysis establishes that, nine (9) out of those ten (10) CSFs observed to have the level of criticality is 'High'. The only factor, organisational capabilities to transfer and share tacit knowledge is observed, as the level of criticality is 'Moderately Critical' in both lean and agile processes. The null hypothesis for (V2) is rejected in lean process because the data is not statistically significantly distributed based on Kruskal-Wallis $\mathrm{H}$ test and resultant asymptotic significance ( $p$-value) is calculated lower than (below $<0.05$ ). Similarly, results are calculated for Organisational Capability (V5) and Individual Capability (V6) in agile processes, which reject the null hypothesis. However, Frequency analysis for both the variables establishes that, Organisational Capability (V5) is 'Moderately Critical' to transfer and share tacit knowledge in agile processes.

Table 5: Data Analysis of CSFs to Transfer and Share Tacit Knowledge in both the Lean and Agile Processes

\begin{tabular}{|c|c|c|c|c|c|c|c|}
\hline NO & Critical Success Factor & Processes & Median & $\begin{array}{l}\text { Ordinal } \\
\text { Rank }\end{array}$ & $\begin{array}{l}\text { Statistically } \\
\text { Significantly } \\
\text { Distributed }\end{array}$ & $\begin{array}{l}(p- \\
\text { value })\end{array}$ & $\begin{array}{l}\text { Accept or } \\
\text { Reject } \\
\text { (Null } \\
\text { Hypothesis) }\end{array}$ \\
\hline \multirow{2}{*}{ V1 } & \multirow{2}{*}{$\begin{array}{l}\text { Trust among the organisations in } \\
\text { CSCs }\end{array}$} & Lean & 4 & Critical & Yes & 0.996 & Accept \\
\hline & & Agile & 4 & Critical & Yes & 0.674 & Accept \\
\hline \multirow{2}{*}{$\mathbf{V} 2$} & \multirow{2}{*}{$\begin{array}{l}\text { Motivation to share tacit } \\
\text { knowledge }\end{array}$} & Lean & 4 & Critical & NO & 0.012 & Reject \\
\hline & & Agile & 4 & Critical & Yes & 0.064 & Accept \\
\hline \multirow{2}{*}{$\mathbf{V 3}$} & \multirow{2}{*}{$\begin{array}{l}\text { Leadership capabilities of clients } \\
\text { and main contractors to encourage } \\
\text { sharing tacit knowledge }\end{array}$} & Lean & 4 & Critical & Yes & 0.254 & Accept \\
\hline & & Agile & 4 & Critical & Yes & 0.177 & Accept \\
\hline \multirow{2}{*}{ V4 } & \multirow{2}{*}{$\begin{array}{l}\text { Business strategies aligned to } \\
\text { share tacit knowledge in } \\
\text { organisations within construction } \\
\text { process }\end{array}$} & Lean & 4 & Critical & Yes & 0.539 & Accept \\
\hline & & Agile & 4 & Critical & Yes & 0.562 & Accept \\
\hline \multirow{2}{*}{ V5 } & \multirow{2}{*}{$\begin{array}{l}\text { Organisations within CSC must } \\
\text { have Capabilities to Share tacit } \\
\text { knowledge }\end{array}$} & Lean & 3 & $\begin{array}{l}\text { Moderately } \\
\text { Critical }\end{array}$ & Yes & 0.539 & Accept \\
\hline & & Agile & 3 & $\begin{array}{l}\text { Moderately } \\
\text { Critical }\end{array}$ & NO & 0.022 & Reject \\
\hline \multirow{2}{*}{ V6 } & \multirow{2}{*}{$\begin{array}{l}\text { Individual involved } \\
\text { construction process must be } \\
\text { capable to share tacit knowledge }\end{array}$} & Lean & 4 & Critical & Yes & 0.717 & Accept \\
\hline & & Agile & 4 & Critical & NO & 0.005 & Reject \\
\hline \multirow{2}{*}{ v7 } & \multirow{2}{*}{$\begin{array}{lcr}\text { Identification } & \text { of process } \\
\text { improvement } & \text { opportunity by } \\
\text { managers } & & \end{array}$} & Lean & 4 & Critical & Yes & 0.286 & Accept \\
\hline & & Agile & 4 & Critical & Yes & 1.286 & Accept \\
\hline \multirow{2}{*}{ v8 } & \multirow{2}{*}{$\begin{array}{l}\text { Identification of type of } \\
\text { Knowledge to Share }\end{array}$} & Lean & 4 & Critical & Yes & 0.87 & Accept \\
\hline & & Agile & 4 & Critical & Yes & 0.735 & Accept \\
\hline \multirow{2}{*}{ V9 } & \multirow{2}{*}{$\begin{array}{l}\text { Identification of Source of } \\
\text { Knowledge }\end{array}$} & Lean & 4 & Critical & Yes & 0.054 & Accept \\
\hline & & Agile & 4 & Critical & Yes & 0.251 & Accept \\
\hline \multirow{2}{*}{ V10 } & \multirow{2}{*}{$\begin{array}{l}\text { Identification of Knowledge } \\
\text { Recipient }\end{array}$} & Lean & 4 & Critical & Yes & 0.522 & Accept \\
\hline & & Agile & 4 & Critical & Yes & 0.603 & Accept \\
\hline
\end{tabular}

\section{Correlation between CSFs}


The Spearman's correlation analysis is run to identify the correlation significance among the CSFs, which enables transfer and share tacit knowledge in the application of both the lean and agile processes.

\section{Correlation of CSFs to transfer and share Tacit Knowledge in both the (a) Lean and (b) Agile Processes}

(a) Correlation of CSFs in Lean Processes

The most significant correlation ( $r_{s}=.775$ ) has been found between (V9) and (V10). This reflects that, the identification of both the source and recipient of knowledge are essential CSFs.

The second highest and positive correlation coefficient ( $\left.r_{s}=.595\right)$ is calculated between (V8) and (V9) and the third highest ( $r_{s}=.585$ ) is between (V8) and (V10). Among the forty-five (45) correlations, a negative correlation is found between (V1) and (V9), calculated as $\left(r_{s}=-.042\right)$.

(b) Correlation of CSFs in Agile Processes

In agile processes, the most significant correlation $\left(r_{s}=.719\right)$ has been found between (V8) and (V10). This reflects that, the identification of both, the type of knowledge and recipient of knowledge are essential and are highly correlated CSFs.

The second highest and positive correlation coefficient ( $\left.r_{s}=.657\right)$ is calculated between (V9) and (V10). This portrays that identification of both, the source and recipient of knowledge are also highly correlated CSFs.

The third highest significant correlation coefficient $\left(r_{s}=.651\right)$ is found between (V8) and (V9). This reflects that, the identification of both, the type of knowledge and source of knowledge are essential CSFs to Transfer and Share Knowledge in Agile Processes and are highly correlated with each other.

The fourth highest correlation coefficient $\left(r_{s}=.594\right)$ is found between (V3) and (V4). This establishes that, to encourage transfer and sharing tacit knowledge in agile processes leadership capabilities of clients and main contractors are highly correlated with business strategies. Moreover, the fifth highest positive correlation coefficient ( $\left.r_{s}=.499\right)$ is recorded between (V3) and (V5). This establishes that, along with business strategies (V4), leadership capabilities are also highly correlated with organisational capabilities (V5).

(c) Interpretive analysis of correlations between CSFs

Table (6) below exhibits the rank order among the CSFs from 'Highest Correlated Coefficient' to 'Lowest Correlated Coefficient'. The following three (3) assumptions are made in respect to 'highest to lowest' correlation coefficient of CSFs (V1 to V10) in lean processes. These assumptions are restricted to three (3) based on (Rank 1-3) to avoid duplication and developing confusion interpreting presumptions.

(d) Interpretive correlation coefficient rank orders of CSF's: Lean processes

Table 6: Interpretive Correlation Coefficient Ranking Orders of CSFs in Lean Processes 


\begin{tabular}{|c|c|c|c|c|c|c|c|c|c|c|c|c|c|}
\hline \multirow{2}{*}{\multicolumn{2}{|c|}{ Rank }} & \multicolumn{10}{|c|}{ Success Factors } & \multirow{2}{*}{ Frequency - Times } & \multirow{2}{*}{ Rank } \\
\hline & & V1 & V2 & V3 & V4 & V5 & V6 & V7 & V8 & V9 & V10 & & \\
\hline \multirow{3}{*}{ 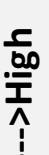 } & 1 & $\mathrm{~V} 2$ & V1 & V1 & V8 & V6 & V5 & V9 & V9 & V10 & V9 & V9-3, V1-2 & \begin{tabular}{|l|l}
$1\}$ & $x$ \\
1
\end{tabular} \\
\hline & 2 & V3 & V7 & V4 & V3 & V1 & V3 & V10 & V10 & V8 & V8 & V3-3, V8-2, V10-2 & $2 \sqrt{2}$ \\
\hline & 3 & V5 & V9 & V6 & V7 & V3 & V9 & V8 & V7 & V7 & V7 & V7-4, V9- 2 & \\
\hline \multirow{6}{*}{ 3. } & 4 & V4 & V3 & V7 & V10 & V4 & V7 & $\mathrm{V} 2$ & V4 & V6 & V4 & V4-4, V7- 2 & 24 \\
\hline & 5 & V7 & V5 & V5 & V9 & V7 & V10 & V3 & V6 & V4 & V6 & V5-2, V6-2, V7 - 2 & 5 \\
\hline & 6 & V6 & V8 & V9 & V5 & $\mathrm{V} 2$ & V4 & V4 & V2 & V3 & V3 & V2-2, V3-2, V4 - 2 & 6 \\
\hline & 7 & V10 & V10 & $\mathrm{V} 2$ & V1 & V9 & V8 & V6 & V3 & $\mathrm{V} 2$ & $\mathrm{~V} 2$ & V2-2, V10 - 2 & 군 \\
\hline & 8 & V8 & V6 & V10 & V6 & V8 & V1 & V5 & V5 & V5 & V5 & V5-4, V6-2, v8 - 2 & 80 \\
\hline & 9 & V9 & V4 & V8 & V2 & V10 & V2 & V1 & V1 & V1 & V1 & $\mathrm{V} 1-4, \mathrm{~V} 2-2$ & {$[9]$} \\
\hline
\end{tabular}

1 In rank (1)

a. In above table 6 CSF (V9) appeared three times, based on highest correlation coefficient. CSF (V9) has positive correlation coefficient with (V7), (V8) and (V10).

Secondly, CSF (V1) has appeared two times and that have positive correlation coefficient with (V2) and (V3).

This establishes that, identifying source of knowledge (V9) is the foremost CSF, which highly required identification of type of knowledge to transfer and share (V8) and further, identification of knowledge recipient (V10). Similarly, trust among organisations (V1) required motivation to transfer and share tacit knowledge (V2) and leadership capabilities to encourage transfer and share tacit knowledge.

2 In (Rank 2)

a. Following the (Rank 1), CSF (V3) has positive correlation coefficient with (V1), (V4) and (V6). This establishes the assumption that, Leadership Capabilities to encourage transfer and share knowledge (V3) requires aligned business strategies to transfer and share tacit knowledge in organisations (V4) and further requires capabilities of individuals to transfer and share tacit knowledge within the construction processes (V6).

3 In (Rank 3)

a. CSF (V7) correlates with (V4), (V8), (V9) and (V10). This highlights that, identification of process improvement opportunity (V7) is also an essential CSF to relate with (Rank 1) and assumption (1) with CSFs (V8), (V9) and (V10). This establishes that, before identifying CSF's (V8), (V9) and (V10) it is vital to identify the process improvement opportunity by managers (V7).

(e) Interpretive correlation coefficient rank orders of CSF's: Agile processes

Table 7: Interpretive Correlation Coefficient Ranking Orders of CSFs in Agile Processes 


\begin{tabular}{|c|c|c|c|c|c|c|c|c|c|c|c|c|c|}
\hline \multirow{2}{*}{\multicolumn{2}{|c|}{ Rank }} & \multicolumn{10}{|c|}{ Success Factors } & \multirow{2}{*}{ Frequency - Times } & \multirow{2}{*}{ Rank } \\
\hline & & V1 & V2 & V3 & V4 & V5 & V6 & V7 & V8 & V9 & V10 & & \\
\hline \multirow{3}{*}{ 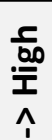 } & 1 & $\mathrm{~V} 2$ & V1 & V4 & V3 & V3 & V9 & V10 & V10 & V10 & V8 & V10 - 3, V3 - 2 & \\
\hline & 2 & V5 & V9 & V5 & V5 & V6 & V5 & V6 & V9 & V8 & V9 & V5-4, V6-2, V9-2 & \\
\hline & 3 & V4 & V8 & V1 & V1 & V1 & V7 & V9 & V3 & V2 & V7 & V1 - 3, V7 - 2 & \\
\hline \multirow{6}{*}{ 3̧ } & 4 & V3 & V5 & V9 & V8 & V4 & V10 & V8 & V7 & V6 & V6 & V6-2, V8 - 2 & \\
\hline & 5 & V6 & V3 & V2 & V9 & V9 & V2 & V2 & V4 & V7 & V4 & V2-3, V4-2, V9-2 & \\
\hline & 6 & V9 & V6 & V8 & V10 & $\mathrm{V} 2$ & V1 & V5 & V5 & V5 & V2 & V5-3, V2 - 2 & \\
\hline & 7 & V8 & V7 & V6 & V6 & V7 & V7 & V4 & V6 & V4 & V1 & V6-3, V7-3 & $=$ \\
\hline & 8 & V10 & V10 & V7 & $\mathrm{V} 2$ & V8 & V3 & V3 & V3 & V3 & V5 & V3-4, V10-2 & ㄴㅇㅢ 울 \\
\hline & 9 & V7 & V4 & V10 & V7 & V10 & V4 & V1 & V1 & V1 & V3 & V1-3, V4-2, V7-2, & [9] \\
\hline
\end{tabular}

1 In rank (1),

a. In above table 7, CSF (V10) has positive correlation coefficient with (V7), (V8) and (V9) and (V3) have positive correlation coefficient with (V4) and (V5). This establishes that, identifying recipient of knowledge (V10) is the foremost CSF. The frequency of highest correlation coefficient of V10 is three (3). This is highly correlated with the identification of process improvement opportunity (V7), type of knowledge to transfer and share (V8) and further, identification of knowledge source (V9).

b. Leadership capabilities of clients and main contractors (V3) appeared two times in rank one (table 7). Here (V3) required business strategies aligned to transfer and share tacit knowledge (V4) and (V5) organisational capabilities to transfer and share tacit knowledge.

2 In (Rank 2),

a. Following the (Rank 1, in table 7), CSF (V5) has positive correlation coefficient with (V1), (V3), (V4) and (V6). This establishes the assumption that, Organisational Capabilities to transfer and share knowledge (V5) requires trust among organisations (V1), leadership capabilities of clients and main contractors (V3), aligned business strategies to transfer and share tacit knowledge (V4) and capabilities of individuals involved in construction processes (V6).

b. Furthermore, Capabilities of individuals (V6) requires identification of process improvement opportunity (V7) and nevertheless this requires identification of type of knowledge to transfer and share (V8) and identification of source of Knowledge (V10).

3 In (Rank 3),

a. CSF (V1) is correlated with (V3), (V4) and (V5). This highlights that, trust among organisation within CSCs (V1) correlates with leadership capabilities (V3), Business Strategies (V4) and organisations capabilities (V5).

b. Identification of process improvement opportunity (V7) significantly coefficient with, individuals involved in construction process (V6) and identification of knowledge recipient (V10) this correlates with above assumption (2b). 


\section{Discussion}

A strong relationship between lean and agile is seen through the literature review. Still, this study asks separate questions for lean and agile processes. This is because; existing literature (such as; Court et.al., 2009; Owen and Koskela, 2006) fails to establish that all construction processes are lean and agile processes. Even ifit is established, still, generalising CSFs in application to transfer and share tacit knowledge within a lean and agile construction process would require further investigation to generalise the lean and agile attributes. Therefore, the current understanding is that some processes are purely lean process and/or purely agile process. Therefore, this study discusses lean and agile processes separately. On those grounds, this study also considers that, asking question about lean and agile would bring ambiguity and bias, which leaves the views of lean and agile (Leagile) thinkers ignored. Resultant, this would not justify the distinct views of dominant community of practice of lean and agile practitioners within the construction sector. Consequently, the results of this study are not generalised and presented separately for lean and agile processes.

The first set of question aimed to investigate the CSFs in application of transfer and sharing tacit knowledge in lean construction processes and the second set aims on agile construction processes. To distinguish between these two processes (lean and agile) the statistical analysis has been performed separately.

In the lean process, the study establishes that, identifying the source of knowledge is the foremost $\mathrm{CSF}$, which requires to identifying the type of knowledge to transfer and share and further requires identification of knowledge recipient.

However, in agile processes, the foremost CSF is identifying the knowledge recipient. This further requires identifying the process improvement opportunity followed by type of knowledge to share and lastly identification of source of knowledge.

Furthermore, in lean construction process, trust among organisations is observed as the second CSF, which requires 'motivation' and further motivation is required to identify type of knowledge to transfer and share. However, motivation should be supported with leadership and organisational capabilities. On the contrary, in agile process, leadership capabilities are the second most CSF, which require business strategies aligned and further require organisational capabilities and trust among organisations. Motivation ranks three of agile process, which requires alignment with leadership and organisational capabilities. Both lean and agile processes require individual capabilities.

\section{Implication of CSFs in Lean and Agile Construction Processes}

The primary goal of KM is to transfer and share tacit knowledge from one person to another, to solve a specific problem or handle a particular task. The other goal of KM is to ensure that knowledge is available when required with the required speed and accuracy. Lin and Tserng, (2003) stated that, tacit knowledge particularly can be reused for other current and future projects to avoid repeating the same or similar mistakes. However, the transfer and share of tacit knowledge is based on the context specific knowledge. That needs clear business strategy by project leaders (Trees and Lemons, 2014). This also needs the identification of which type of knowledge require update. Afterwards, it needs identifying which process to update and finally identifying the source of the knowledge. Trees and Lemons, (2014) highlighted that, before transferring and sharing tacit knowledge, an organisation 
must define a strategy and identify a process to protect critical knowledge. Previous studies indicate that the first requirement of knowledge transfer is to identify the control variables.

As pointed out in literature review and in rank order analysis, below figure 2 presents, the variables that control initiation of transfer and share tacit knowledge are (1) leadership capabilities, (2) trust, (3) motivation, (4) business strategies, (5) organisational capabilities and (6) individual capabilities. Figure 2 below also exhibits, the knowledge transfers and sharing process based on the data analysis of CSFs in lean and in agile separately. The data analysis establishes that Identifying process improvement opportunity is important before identifying the source of knowledge in a lean process. In an agile process, the source of knowledge is pre-known, but managers need to understand how that knowledge should be used to improve the process. In both lean and agile processes, as discussed in literature review, lean and agile have different attributes. Therefore, figure (2) below show that in an agile construction process, the predominant factor to identify the recipient of knowledge. It presents that the knowledge is available beforehand to improve a process. This is because, an agile process is having obligatory information enrichment and consultative nature of forecasting mechanism (see table 1). Therefore, the results from both the lean and the agile are exhibited together in figure (3).
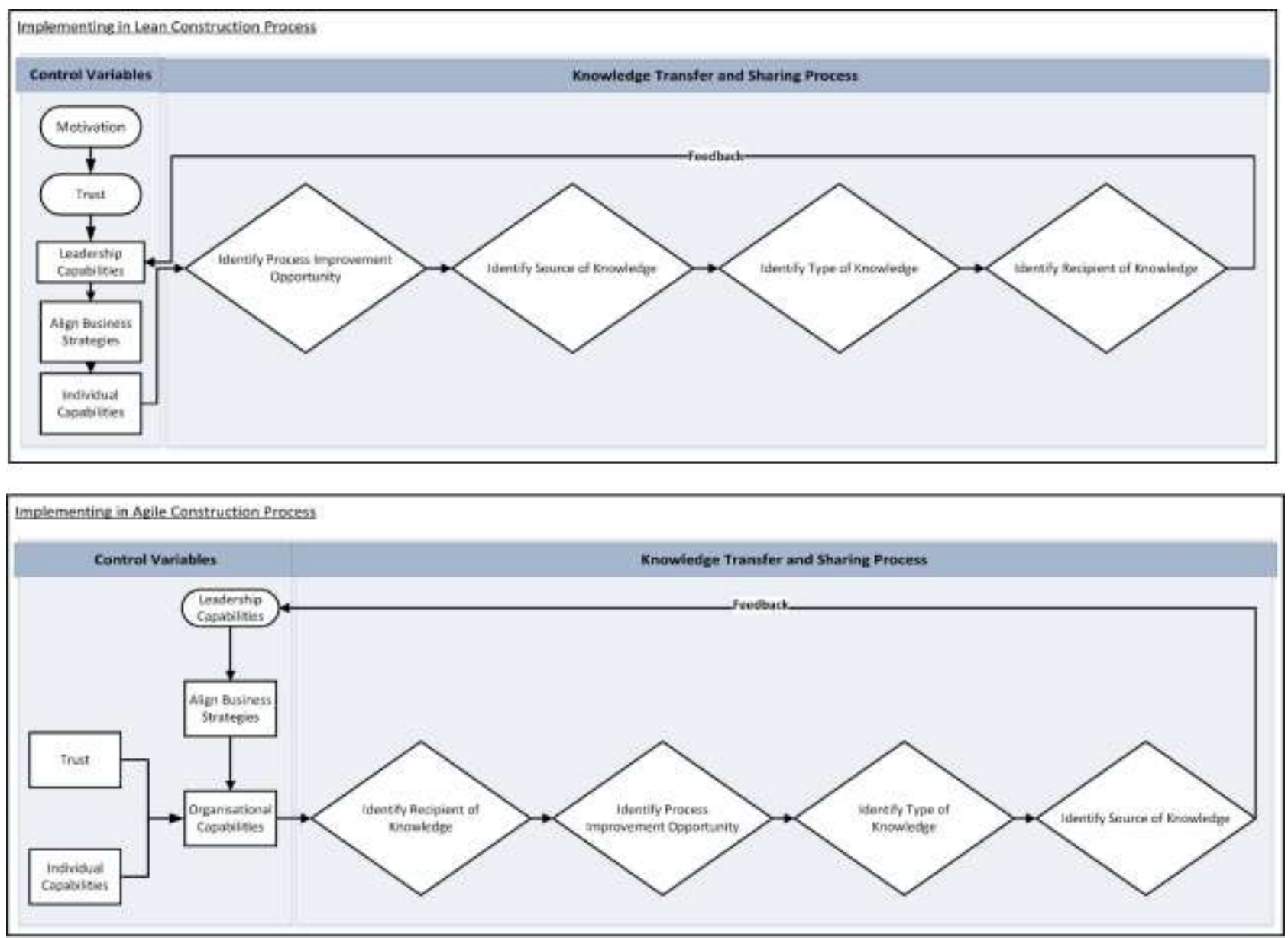

Figure 2: Implementing Knowledge Transfer and Sharing in Construction Process

A large number of published studies (Court et al., 2009; Mason-jones et al., 2000; Naylor et al., 1999; Sabri and Shaikh, 2010) suggest combining the lean and the agile principles to maximise the benefits. Figure (3) below exhibits the generalised results of implementing knowledge transfer and sharing in a lean and agile process. In this, agile process can be taken as a stage two of knowledge transferring 
and sharing process. This is because, the knowledge transfer and sharing in a lean process creates a new knowledge.

In figure (3), identifying the recipient of knowledge is the point where lean and agile processes meet. In the lean process, knowledge sharing is driven by identifying process improvement opportunity. Here, the problems that need attention are predefined and knowledge sharing is needed (managers look for source of knowledge) to overcome the problem. On the other side, in the agile process, readily available knowledge is shared to prevent potential problems.

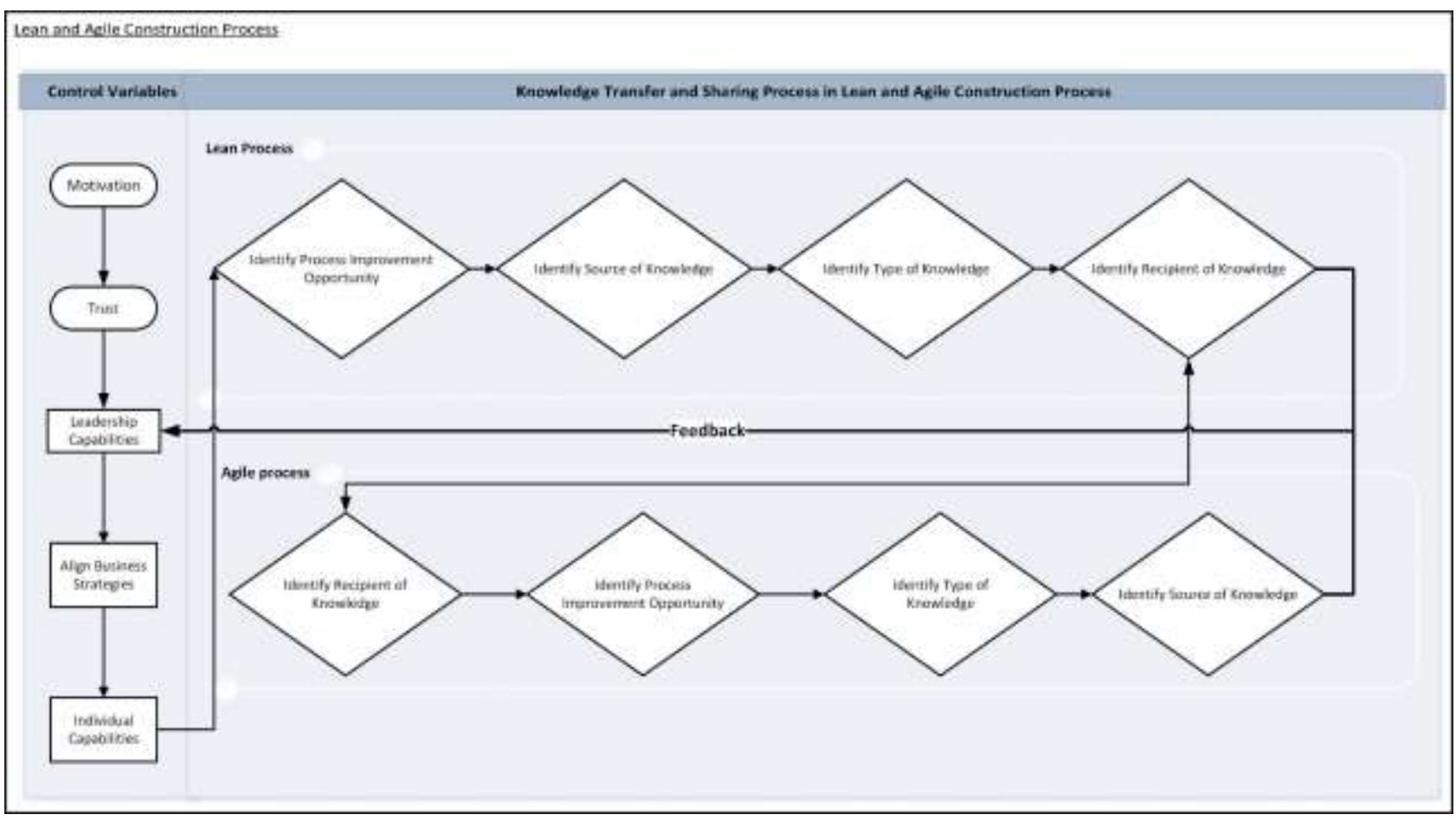

Figure 3: Implementing Knowledge Transfer and Sharing in Lean and Agile Construction Process

\section{Conclusion}

Adopting just lean or just agile in construction process does not bring collaboration in a CSC. The lean principle is widely considered to reduce waste and lead-time in a supply chain (Womack and Jones, 2003; Womack et al., 1990) and agility is merely considered as being responsive to unpredictable demands and markets (Christopher and Towill, 2001; Mason-jones et al., 2000). Both the lean and agile principles demand the collaboration between source and recipient of knowledge to create new knowledge. It will be unfair to say that a CSC is entirely based on just lean or agile principles (Saini, 2015).

This study identifies the CSFs to facilitate the transfer and sharing of tacit knowledge in lean and agile construction processes. The investigation of the CSFs concludes with some interesting facts. The literature review concludes that trust among organisations and individuals are to be the predominant CSF. However, above quantitative analysis demonstrates that identifying the source of knowledge is the leading CSF that is essentially required to identify the type of knowledge to transfer and share, in addition to the identification of the knowledge recipient, in lean processes. However, in agile processes, the foremost CSF is determined to be the identifying of the knowledge recipient. This further requires identifying the process improvement opportunities followed by the type of knowledge to share and, lastly, identification of the source of knowledge. 
The literature review also concludes that leadership capabilities are the second most important CSF aligned with business strategies to initiate transfer and share of tacit knowledge. Trust between organisations is paramount. Moreover, quantitative analysis establishes that business strategies and individual capabilities driven by leadership are equally important. The standardised results from the literature review and the quantitative analyses conclude that identifying process improvements opportunity is the most predominant CSF but there must be an equal consideration of trust, leadership capability, corporate strategies, and motivation.

However, to make a KM initiative successful within lean and agile processes, people and organisations require skills and training in developing their capabilities in order to ensure the smooth transferring and sharing of tacit knowledge.

The study aims to provide a novel perspective to one of the most important gap in literature of construction processes while developing new literature of knowledge management and framework (figure 2 and 3) that establish that how Tacit Knowledge can be transferred and shared. This research establishes the CSFs associated to effectiveness of knowledge sharing in lean and agile construction processes. The development of the framework (figure 2 and 3) in this study fills the gap in existing literature and the lack of KM frameworks for transferring and sharing Tacit Knowledge. In addition, the study has potential to direct further research into effective communication to transfer and share tacit knowledge in construction and other industries.

In practice, at managerial levels (tier 2 and above) of a CSC, this study provides a roadmap to remodelling existing policies concerning managing knowledge to facilitate construction project efficiency and collaboration and partnering among stakeholders of a construction project. In addition, this study may simulate Lean, Agile, KM and SC communities (not just in the construction sector) to rethink the role and importance of KC. The CSFs evolved from this study could also influence other closely related industries in terms of a knowledge transfer and sharing approach. Moreover, findings from the data analysis can lead to further research based on each hypothesis. In addition, the framework to transfer and share tacit knowledge can be further tested in practice and can be adopted in different contexts.

Nevertheless, to initiate knowledge communication in construction processes, there may be certain set of individual capabilities that are required for the source and the recipient of knowledge. Study by (Saini, 2015) concludes that individuals (source and recipient of knowledge) will require observational, absorptive, knowledge application, dissemination, explanation, and conversational and routing capabilities. However, to make a KM initiative successful within Lean and Agile processes, people and organisations require skills and training in developing their capabilities in order to ensure the smooth transferring and sharing of tacit knowledge. Therefore, this study has potential to developing new literature on knowledge management and establishing the ways of $\mathrm{KC}$ to transfer and share tacit knowledge. Therefore, in terms of individual capabilities to transfer and share knowledge, this study can be taken as a starting point to construct a basis for further research on the type of skills and training which should be provided to employees.

The study is limited to the UK construction sector and thus it cannot be generalised universally without further research in other countries and regions throughout the world. A similar study in another sector or country might highlight a different set of CSF's for the transfer and sharing of tacit knowledge. Therefore, it is important to undertake a sector- specific study and test the findings of this study. The use of a survey questionnaire with questions in the areas of supply chain, lean, Agile and KM limits the scope of employing a wider population to be tested for their perceptions. Moreover, this study is limited to utilising experts who have a knowledge and understanding of the lean and agile and KM principles in the construction process. The named CSF's can be further analysed separately while taking this study as a starting point. 


\section{References}

Abbas, N., Gravell, A.M. and Wills, G.B. (2008), "Historical roots of agile methods: Where did 'Agile thinking' come from?”, Lecture Notes in Business Information Processing, Vol. 9 LNBIP, University of Southampton, Southampton, pp. 94-103.

Alashwal, A. M., Rahman, H. A., and Beksin, A. M. (2011). Knowledge sharing in a fragmented construction industry: On the hindsight. Construction, 6(7), 1530-1536.

Alavi, M. (1999). Knowledge Management Systems: Issues, Challanges, and Benefits. CAIS, 1(February), 1-37.

Alavi, M., and Leidner, D. (2001). Review: Knowledge management and knowledge management systems: Conceptual foundations and research issues. MIS Quarterly.

Al-Hawamdeh, S. (2002). Knowledge management: re-thinking information management and facing the challenge of managing tacit knowledge'. Information Research, 8(1).

Anumba, C., Egbu, C., and Carrillo, P. (2008). Knowledge management in construction (1st ed.). Oxford: Blackwell Publishing Ltd.

Arif, M., Mohammed, A.-Z., and Aman Deep, G. (2015). Understanding knowledge sharing in the Jordanian construction industry. Construction Innovation, 15(3), 333-354.

Aziz, Z., Saini, M., Tazel, A. and Arif, M. (2016), Advancing the Implementation of Lean within Highways England's Small and Medium Sized Enterprises ( SMEs ), Report, University of Salford. (Unpublished)

BIS. (2011a), Infrastructure Supply Chains: Barriers and Opportunities, Department for Business, Innovation and Skills. London.

BIS. (2011b), Building Information Modelling (BIM) Working Party Strategy Paper, London.

BIS. (2013). Small business survey 2012: sme employers : Report: BMG Research.

Bou-Llusar, J. C., and Segarra-Ciprés, M. (2006). Strategic knowledge transfer and its implications for competitive advantage: an integrative conceptual framework. Journal of Knowledge Management, 10(4), 100-112.

Capgemini. (2004). Business Process Modeling Defined. CDC.gov: Retrieved November 20, 2015, from http://www.cdc.gov/std/program/bpmm/Overview.pdf

Ceric, A. (2012). Communication risk in contruction Projects: Application of principal-agent theory. Organization, Technology and Management in Construction: An International Journal, 4(2), 522-533.

Chen, N., and Zhang, X. (2014). A Dynamic Observation Capability Index for Quantitatively PreEvaluating Diverse Optical Imaging Satellite Sensors. Journal of Selected Topics in Applied Earth Observations and Remote Sencing, 7(2), 515-530.

Christopher, M., and Towill, D. (2001). An integrated model for the design of agile supply chains. International Journal of Physical Distribution and Logistics Management, 31(4), 235-246.

Coakes, E., and Clarke, S. (2005). Encyclopedia of Communities of Practice in Information and 
Knowledge Management. (E. Coakes and S. Clarke, Eds.). IGI Global.

Court, P., Pasquire, C., Gibb, A., and Bower, D. (2009). Design of a lean and agile construction system for a large and complex mechanical and electrical project. In IGCL14 (pp. 1-14).

Cuttance, P., and Ecob, R. (2009). Structural Modeling by Example: Application in Educational, Sociological and Behavioral Research (1st ed.). New York: Cambridge University Press.

Egan, J. (1998). Rethinking construction: the report of the Construction Task Force. London: Department of the Environment, Transport and the Regions Construction Task Force.

Egbu, C. O., Anumba, C. J., and Carrillo, P. M. (2005). Knowledge Management in Construction. (C. O. E. and P. M. C. Chimay J. Anumba, Ed.). Blackwell Publishing Ltd.

Fischer, L. (2013). Empowering Knowledge Workers: New Ways to Leverage Case Management. Florida, USA: Future Strategies Inc.

Goh, S. C. (2002). Managing effective knowledge transfer: an integrative framework and some practice implications. Journal of Knowledge Management, 6(1), 23-30.

Hughes, W., Hillebrandt, P. M., Greenwood, D. G., and Kwawu, W. E. K. (2002). Developing a system for assessing the costs associated with different procurement routes in the construction industry. Construction Innovation and Global Competitiveness, 1, 826-840.

Ishibuchi, H., Kaisho, Y., and Nojima, Y. (2009). Complexity, interpretability and explanation capability of fuzzy rule-based classifiers. IEEE International Conference on Fuzzy Systems, 1730-1735.

Issa, R. R. a., and Haddad, J. (2008). Perceptions of the impacts of organizational culture and information technology on knowledge sharing in construction. Construction Innovation: Information, Process, Management, 8(3), 182-201.

Jetter, A., Kraaijenbrink, J., Schröder, H.-H. and Wijnhoven, F. (2006), “Knowledge Integration: The Practice of Knowledge Management in Small and Medium Enterprises”, Physica-Verlag- A Springer Comapany, New York.

Kagioglou, M., and Cooper, R. (2012). Re-engineering the UK construction industry: the process protocol. University of Salford. Salford.

Keraminiyage, K. (2009). Achieving high process capability maturity in construction organisations. The University of Salford.

Khalfan, M. M. a., McDermott, P., and Swan, W. (2007). Building trust in construction projects. Supply Chain Management: An International Journal, 12(6), 385-391.

Kivrak, S., and Arslan, G. (2008). Capturing knowledge in construction projects: Knowledge platform for contractors. Journal of Management in Engineering, 24(2), 87-96.

Konukcu, S. (2011). A knowledge chain framework for construction supply chains. Loughborough University.

Krishnamurthy, R., and Yauch, C. a. (2007). Leagile manufacturing: a proposed corporate infrastructure. International Journal of Operations and Production Management, 27(6), 588604.

Lau, E. and Rowlinson, S. (2010), “Trust relations in the construction industry”, International Journal of Managing Projects in Business, Vol. 3 No. 4, pp. 693-704. 
Lau, E., and Rowlinson, S. (2011). The implications of trust in relationships in managing construction projects. Journal of Managing Projects in Business, 4(4), 633-659.

Lin, Y., and Tserng, H. (2003). Knowledge Management and its application to Lean Construction. International Group for Lean Construction. Lean Construction: København.

Lomax, S., Wiseman, J. and Perry, E. (2013), SMALL BUSINESS SURVEY 2012: SME EMPLOYERS : A Report by BMG Research, Department of Business Innovation and Skills. BMG Research Ltd. London

Maier, R. (2007). Knowledge management systems: Information and communication technologies for knowledge management (3rd ed.). New York: Springer Berlin.

Markie, P. (2004). Rationalism vs. Empiricism. Stanford Encyclopaedia of Philosophy: Sanford

Mason-jones, R., Naylor, B. and Towill, D.R. (2000), "Engineering the leagile supply chain", International Journal of Agile Management Systems, Vol. 2 No. 1, pp. 54-61.

McDermott, P., Khalfan, M., and Swan, W. (2005). Trust in construction projects. Journal of Financial Management of Property and Construction, 10(1), 19 - 32.

McLean, L. (2004). A Review and Critique of Nonaka and Takeuchi's Theory of Organizational Knowledge Creation. In Paper presented at the Fifth International Conference on HRD Research and Practice across Europe by AHRD and UFHRD (Vol. 1).

Narteh, B. (2008). Knowledge transfer in developed-developing country interfirm collaborations: a conceptual framework. Journal of Knowledge Management, 12(1), 78-91.

Nasrun, M., Nawi, M., Baluch, N. and Bahauddin, A.Y. (2014), "Impact of Fragmentation Issue in Construction Industry : An Overview 3 Discussions : Fragmentation Issue”, Building Surveying, Facilities Management and Engineering Conference, Vol. 15, EDP Sciences, p. 8.

Naylor, J.B., Naim, M.M. and Berry, D. (1999), "Leagility: Integrating the lean and agile manufacturing paradigms in the total supply chain”, International Journal of Production Economics, Vol. 62 No. 1-2, pp. 107-118.

Orange, G., Burke, A., and Boam, J. (1994). Organisational Learning in the UK Construction Industry: A Knowledge Management Approach. Leeds.

Owen, R., and Koskela, L. (2006). Is agile project management applicable to construction? In IGCL (pp. 51-66). Santiago, Chile.

Pathirage, C. (2007). A Structured Approach To Manage The Tacit Knowlwdge of Construction Employees. Thesis. University of Salford.

Perez, A.G. and Benjamins, V.R. (1999), Overview of Knowledge Sharing and Reuse Components : Ontologies and Problem-Solving Methods, IJCAI-99 Workshop on Ontologies and ProblemSolving Method (KRR5), Stockholm, Sweden.

Pinto, M.S. (2007), Performance Modeling and Knowledge Processing in High-Speed Interconnected Intelligent Educational Networks, ProQuest,

Polanyi, M. (2009). The Tacit Dimension. (A. Sen, Ed.) (5th ed.). University of Chicago Press.

Polanyi, M. (2012). Personal Knowledge: Towards a Post-Critical Philosophy. London: University of Chicago Press.

Rahimnia, F., and Moghadasian, M. (2010). Supply chain leagility in professional services: how to 
apply decoupling point concept in healthcare delivery system. Supply Chain Management: An International Journal, 15(1), 80-91.

Rao, M. (2012), Knowledge Management Tools and Techniques: Practitioners and Experts Evaluate KM Solutions, edited by Rao, M., Elsevier Butterworth-Heinemann, Oxford

Reich, B. H., Gemino, A., and Sauer, C. (2012). Knowledge management and project-based knowledge in it projects: A model and preliminary empirical results. International Journal of Project Management, 30(6), 663-674.

Reimer, U., and Karagiannis, D. (2008). Practical Aspects of Knowledge Management. In J. S. Jaime G. Carbonell (Ed.), 6th International Conference, PAKM (p. 348). Vienna: Springer-Verlag Berlin Heidelberg.

Ribeiro, F. L., and Fernandes, M. T. (2010). Exploring agile methods in construction small and medium enterprises: a case study. Journal of Enterprise Information Management, 23(2), 161180.

Sabri, E.H. and Shaikh, S.N. (2010), Lean and Agile Value Chain Management: A Guide to the Next Level of Improvement, J. Ross Publishing

Sacks, R., Dave, B.A., Koskela, L. and Owen, R. (2009), “Analysis framework for the interaction between lean construction and building information modelling”, International Group for Lean Construction,

Saini, M. (2015). A framework for transferring and sharing tacit knowledge in construction supply chains within lean and agile processes. Thesis: University of Salford.

Schwartz, D. G. (2005). Encyclopedia of Knowledge Management. (D. Schwartz, Ed.). Israell: IGI Global.

Taylor, S. (2012). Offsite Production in the UK Construction Industry. Report: Construction Engineering Specialist Team: HSE

Thomas, J. S. (2013). A Brief History Of Knowledge Management. Retrieved August 4, 2013, from http://johnsthomas.wikidot.com/a-brief-history-of-km

Tiwana, A. (1999). The knowledge management toolkit: practical techniques for building a knowledge management system. International immunology (Vol. 25). London: Prentice Hall.

Weber, J. M., Malhotra, D., and Murnighan, J. K. (2005). Normal actss of irrational trust: motivated attributions and the trust development process. Research in Organizational Behavior, 26, 75101.

Womack, J., and Jones, D. (2003). Lean Thinking: Banish Waste and Create Wealth in Your Corporation (1st ed.). NY: Free Press.

Womack, J.P., Jones, D.T., Roos, D. and Carpenter, D.S. (1990), THE MACHINE THAT CHANGED THE WORLD., Macmillan Publishing Company, New York

Wong, K. Y. (2005). Critical success factors for implementing knowledge management in small and medium enterprises. Industrial Management and Data Systems, 105(3), 261-279.

Yusuf, Y. Y., Sarhadi, M., and Gunasekaran, A. (1999). Agile manufacturing : The drivers , concepts and attributes, 62(Int. J. Production Economics), 33-43.

Zhang, P. (2012). Attitude toward knowledge sharing in construction teams. Industrial Management and Data Systems, 112(9), 1326-1347. 
